\title{
Expression of the adrenomedullin binding protein, complement factor $H$, in the pancreas and its physiological impact on insulin secretion
}

\author{
A Martínez, R Pío, J López ${ }^{1}$ and F Cuttitta \\ Department of Cell and Cancer Biology, National Cancer Institute, National Institutes of Health, Bethesda, Maryland 20892, USA \\ ${ }^{1}$ Cell Biology Unit, Department of Biology, Universidad Autónoma de Madrid, Cantoblanco, Madrid, Spain \\ (Requests for offprints should be addressed to A Martínez, Department of Cell and Cancer Biology, National Cancer Institute, National Institutes of Health, \\ Building 10, Room 13N262, 9000 Rockville Pike, Bethesda, Maryland 20892, USA; Email: martinea@mail.nih.gov)
}

\begin{abstract}
Adrenomedullin (AM) is a ubiquitous peptide hormone which, among other functional roles, reduces insulin secretion in the pancreas. Recently we have described the interaction between AM and the complement regulator protein factor $\mathrm{H}$, which results in mutual modulation of their respective functions. Here we identify the expression of factor $\mathrm{H}$ in the $\beta$ cells of the rat pancreatic islets by immunohistochemistry and multiple immunofluorescence followed by confocal microscopy. In addition, double immunogold staining under the electron microscope showed coexistence of insulin and factor $\mathrm{H}$ immunoreactivities within the same secretory granules; interestingly, factor $\mathrm{H}$ staining was found in the electron-lucent
\end{abstract}

haloes whereas the insulin antibody labeled preferentially the dense cores. The existence of factor $\mathrm{H}$ mRNA in the pancreas was confirmed by RT-PCR and in situ hybridization. The function of factor $\mathrm{H}$ in the pancreas was investigated with an insulin secretion assay. Addition of factor $\mathrm{H}$ to freshly isolated islets in the presence of AM resulted in a further reduction in insulin secretion with a concomitant elevation of cAMP, suggesting that factor $\mathrm{H}$ increases AM function in glucose homeostasis. The expression of factor $\mathrm{H}$ in the pancreas may play other important roles such as protection against complementmediated cell lysis.

Journal of Endocrinology (2001) 170, 503-511

\section{Introduction}

Adrenomedullin (AM) is a recently recognized pancreatic hormone which is produced in the periphery of the islets of Langerhans, in the same cells that synthesize and secrete pancreatic polypeptide in mammals (Martínez et al. 1996). $\mathrm{AM}$, as well as the other members of its peptide family, amylin and calcitonin gene-related peptide (CGRP), exerts an inhibitory role on glucose-stimulated insulin secretion (Martínez et al. 1996) and, in some cases, may even be responsible for triggering type 2 diabetes (Martínez et al. 1999). This tonic inhibition of insulin release is mediated through a variety of seventransmembrane domain G-protein coupled membrane receptors that have been found in the insulin-producing $\beta$ cells (Martínez et al. 2000). Pancreatic AM seems to have an early origin from both the phylogenetic and ontogenetic points of view. AM has been found in the pancreas of all vertebrate classes, exhibiting a complex pattern of colocalization with other pancreatic hormones, although in some cases it seems to identify a new cell type which contains AM only (López et al. 1999). During embryonal development AM is also present from the very beginning of pancreatic differentiation, indicating some crucial function for this peptide hormone in embryogenesis (Martínez et al. 1998).

Recently, we have identified an AM binding protein in the plasma of several species with an apparent $M_{\mathrm{r}}$ of $120 \mathrm{kDa}$ under non-reducing conditions (Elsasser et al. 1999). When this binding protein was purified to homogeneity and sequenced, database analysis identified our isolated protein as complement factor $\mathrm{H}$, an inhibitor of the alternative pathway of the complement cascade (Pío et al. 2001). Interestingly, factor $H$ had different effects on AM physiology depending on the assays performed. AM-induced increase of cAMP in Rat2 fibroblast cells was augmented in a dose-dependent manner by the exogenous addition of factor $\mathrm{H}$, even though factor $\mathrm{H}$ by itself did not elicit any cAMP response. Factor $\mathrm{H}$ was also shown to elevate the growth stimulatory effect of AM in a breast cancer cell line. On the other hand, addition of factor $\mathrm{H}$ to a receptor-independent AM bactericidal assay resulted in lower killing efficiencies. Interestingly, AM was demonstrated to modify factor $\mathrm{H}$ function by increasing its cofactor activity in the cleavage of C3b by factor I (Pío et al. 2001). 
Given the importance of AM in the regulation of insulin secretion, we decided to study the presence of its binding protein in the pancreas and determine the physiological impact of factor $\mathrm{H}$ in insulin release.

\section{Materials and Methods}

\section{Immunohistochemistry}

Six male albino Wistar rats were euthanized with $\mathrm{CO}_{2}$, and perfused with the fixative (4\% paraformaldehyde) through a heart cannula. The pancreata were extracted and immersed in the same fixative for an additional period of $5 \mathrm{~h}$. After dehydration, the tissues were embedded in paraffin and sectioned following routine procedures.

Two commercially available polyclonal antibodies against human factor $\mathrm{H}$ were used in conjunction with an avidin-biotinylated peroxidase detection kit (Dakopatts, Glostrup, Denmark). The antibodies were goat antihuman factor H (Quidel, San Diego, CA, USA) and rabbit anti-human factor $\mathrm{H}$ (Serotec, Raleigh, NC, USA). To ensure the specificity of the signal, liquid-phase and solid-phase absorption controls were performed with purified human factor $\mathrm{H}$ (Sigma, St Louis, MO, USA). For liquid-phase absorptions, $10 \mathrm{nmol}$ factor $\mathrm{H}$ were added per $\mathrm{ml}$ of optimally diluted antibody for $2 \mathrm{~h}$ at room temperature before incubating the tissue sections. For solid-phase absorptions, factor $\mathrm{H}$ was linked to Ultralink Biosupport Medium (Pierce, Rockford, IL, USA), the optimally diluted antibody was exposed to it for $2 \mathrm{~h}$ at room temperature, and the immune complexes removed by centrifugation.

Neither method resulted in a total abrogation of the signal, therefore we purified the antibody with an affinity chromatography column containing solid-phased factor $\mathrm{H}$. Briefly, $1 \mathrm{mg}$ factor $\mathrm{H}$ was covalently coupled to $250 \mathrm{mg}$ UltraLink Biosupport Medium (Pierce) following the manufacturer's instructions. Rabbit anti-factor $\mathrm{H}$ serum $(250 \mu \mathrm{l})$ was incubated with the resin for $16 \mathrm{~h}$ in $5 \mathrm{ml}$ PBS at $4{ }^{\circ} \mathrm{C}$. Afterwards, the resin was packed in a column and washed intensively with PBS. The bound antibody was eluted with $0.1 \mathrm{M}$ citric acid, $\mathrm{pH} 3.3$. The eluate was neutralized with $1 \mathrm{M}$ sodium phosphate $\mathrm{pH} 8 \cdot 0$, and the buffer changed to PBS by ultracentrifugation in Centricon 50 columns (Amicon, Millipore Corporation, Bedford, MA, USA). Solid-phase absorption of this affinity-purified antibody resulted in a successful quenching of the staining.

\section{Western blotting}

Rat plasma $(1 \mu \mathrm{l})$ from different rats was heated to $95{ }^{\circ} \mathrm{C}$ for $3 \mathrm{~min}$ in the presence of SDS and $\beta$-mercaptoethanol and loaded into the sample well. Purified human factor $\mathrm{H}$ (Sigma) was added in an adjacent lane for comparison. Samples were electrophoretically separated on a gradient
3-8\% Tris-acetate gel (Novex, San Diego, CA, USA), and run at $100 \mathrm{~V}$ for $2 \mathrm{~h}$. Transfer blotting was accomplished in the same apparatus equipped with a titanium plate electrode and transferred to a $0 \cdot 2 \mu \mathrm{m}$ nitrocellulose membrane at $30 \mathrm{~V}$ for $1.5 \mathrm{~h}$. The membrane was blocked overnight with $5 \%$ non-fat dry milk in PBS, and incubated for $1 \mathrm{~h}$ in goat anti factor $\mathrm{H}(1: 2000)$. The membrane was further exposed to peroxidase-bound rabbit anti-goat immunoglobulins (Sigma), 1:10 000 for another hour, and then peroxidase activity was revealed with the ECL+Plus chemiluminescence kit (Amersham, Arlington Heights, IL, USA) following the manufacturer's instructions.

\section{Triple immunofluorescence and confocal microscopy}

To characterize the cell type expressing factor $\mathrm{H}$ immunoreactivity, triple immunofluorescence with primary antibodies raised in three different species was used. After blocking non-specific binding with donkey normal serum (Jackson Immunoresearch Laboratories, West Grove, PA, USA), the paraffin sections were incubated in a mixture of the three primary antibodies. These included a guinea pig anti-bovine insulin 1:2000 (Jackson Immunoresearch Labs), the affinity-purified rabbit anti-human factor $\mathrm{H}$ $1: 200$, and one of three anti-pancreatic peptide monoclonal antibodies. Monoclonal antibodies used in this study include: anti-somatostatin 1:10 000, anti-glucagon 1:1000, and anti-rat pancreatic polypeptide 1:500, all of them from CURE (UCLA, CA, USA). After an overnight incubation at $4{ }^{\circ} \mathrm{C}$, the sections were incubated for $1 \mathrm{~h}$ in the second layer, which was a mixture of Cy5-donkey antiguinea-pig (Jackson Immunoresearch Labs), Bodipy-antimouse (Molecular Probes, Eugene, OR, USA), and biotinylated goat anti-rabbit (Dakopatts), all at a final concentration of 1:200. A third layer containing lissamine rhodamine streptavidin 1:200 (Jackson Immunoresearch Labs) was added for an additional hour. After thorough washes, the slides were mounted in SlowFade solution (Molecular Probes) and observed with a Zeiss Laser Scanning microscope 510, equipped with four lasers.

\section{Electron microscopy}

The pancreata of four additional rats were used for immunoelectron microscopy. Small pieces of the organ were fixed in $1 \%$ glutaraldehyde plus $2 \%$ paraformaldehyde in $0.1 \mathrm{M}$ cacodylate buffer, $\mathrm{pH} 7 \cdot 2$, at $4{ }^{\circ} \mathrm{C}$ for $2 \mathrm{~h}$, dehydrated and embedded in the epoxy resin, TAAB-812 (TAAB Labs, England). Semithin (1 $\mu \mathrm{m}$ thick) sections were stained with methylene blue and used to select areas of interest or subjected to immunohistochemical staining as above.

Ultrathin sections $(60-80 \mathrm{~nm})$ were placed on nickel grids, etched for $5 \mathrm{~min}$ in $3 \% \mathrm{H}_{2} \mathrm{O}_{2}$, and subjected to double immunogold staining as previously described (López et al. 1999). Briefly, the sections were incubated in 
a mixture of both primary antibodies (anti-insulin and anti-factor $\mathrm{H}$ ) at $4{ }^{\circ} \mathrm{C}$ overnight. On the following day, they were exposed to a second layer containing gold particles coupled to the appropriate secondary antibodies (E-Y Laboratories Inc., San Mateo, CA, USA) such that the larger gold particles (20 $\mathrm{nm}$ in diameter) recognized the insulin antibody, and the small particles $(10 \mathrm{~nm})$ the factor $\mathrm{H}$ antibody.

Following thorough rinses, the grids were stained for $15 \mathrm{~min}$ in $5 \%$ aqueous uranyl acetate and for $7 \mathrm{~min}$ in lead hydroxide. The sections were observed in a JEOL-1010 electron microscope.

\section{RT-PCR}

To validate the expression of complement factor $\mathrm{H}$ in the pancreas, an RT-PCR experiment was performed with specific primers. Since the sequence for the rat complement factor $\mathrm{H}$ gene is not available, primers were designed from the mouse gene (GenBank accession number M12660): sense (1877-1896) 5'-TTG-GAATTC-TCC-TGC-CAT-TC-3' and antisense (26442663) 5'-ACC-TTC-CAT-CTT-TGC-ACA-CC-3'. Total RNA was prepared from the liver and pancreas of two $\mathrm{Balb} / \mathrm{c}$ mice, reverse transcribed using the SuperScript Preamplification System (Life Technologies, Gaithersburg, MD, USA), and PCR amplified with eLONGase enzyme mixture (Life Technologies) for 35 cycles, with an annealing temperature of $57^{\circ} \mathrm{C}$. The PCR products were cloned into pCR-Blunt II-TOPO (Invitrogen, Carlsbad, CA, USA) and sequenced by Lark Technologies (Houston, TX, USA). For southern blotting, the PCR products were transferred to a nitrocellulose membrane and an internal probe (2331-2350) 5'-TTGCAA-CAG-ACC-AAC-TGG-AG-3' was end-labeled with standard procedures and used to confirm the specificity of the amplicons.

\section{In situ hybridization}

Detection of factor $\mathrm{H}$ mRNA in rat pancreas was performed using in situ hybridization as previously described (Martínez et al. 1996). The plasmid containing the pancreatic factor H PCR product was linearized with EcoRV and BamHI and used as a template to synthesize digoxigenin-labeled sense and antisense RNA riboprobes. Hybridization was performed in a moist chamber at $42{ }^{\circ} \mathrm{C}$ for $20 \mathrm{~h}$ in a $20 \mu \mathrm{l}$ volume containing $2.5 \mathrm{ng}$ probe/ $\mu \mathrm{l}$. After washes of increasing stringency, visualization of digoxigenin was performed using a digoxigenin detection kit (Boehringer Mannheim, Indianapolis, IN, USA). Controls included the use of the sense probe and digestion with RNase before hybridization.

\section{Islet isolation, insulin secretion and RIAs}

Pancreatic islets were isolated from 12 rats as previously described (Martínez et al. 1996). Briefly, the rats were perfused through the heart with Hank's balanced salt solution (HBSS, Sigma) to remove blood from pancreatic vessels. A small cannula was inserted into the common biliary duct while the coledoco was sealed. A $20-25 \mathrm{ml}$ volume of $0.4 \mathrm{mg} / \mathrm{ml}$ collagenase XI (Sigma) in HBSS was pumped through the cannula until the pancreas was fully inflated. The pancreas was removed and incubated at $37^{\circ} \mathrm{C}$ for $20 \mathrm{~min}$. After that, $20 \mathrm{ml}$ ice-cold HBSS were added and the pancreas dissociated by agitation. After several washes, the islets were collected under a dissecting microscope and distributed into 24-well plates, with a minimum of 70 islets per well.

Freshly isolated islets were incubated in RPMI-1640 (Life Technologies) containing $5.6 \mathrm{mM}$ glucose for $45 \mathrm{~min}$ at $37^{\circ} \mathrm{C}$. The supernatant was saved and the islets incubated in RPMI-1640 containing $20.6 \mathrm{mM}$ glucose plus the potential (anti)secretagogues (AM and/or factor $\mathrm{H}$ ) for another $45 \mathrm{~min}$. The medium was again saved for future analysis and the islets extracted in ice-cold ethanol to measure cAMP contents. Insulin and cAMP were measured by RIA with commercial kits (Amersham), following the manufacturer's protocols.

Insulin release is expressed as a ratio between the insulin concentration in the medium containing high glucose and low glucose, to allow for variations in the number of secreting cells and/or their secretory efficiency. Graphs represent the mean and standard deviation of three wells per treatment. These experiments were performed three times with comparable results. Two-tailed Student's $t$-test was performed to determine statistical significance. $P$ values $<0 \cdot 05$ were considered statistically significant.

\section{Results}

\section{Distribution of factor $H$ immunoreactivity}

The application of all the commercially available antibodies to paraffin-embedded tissue sections of rat pancreas resulted in a clear labeling of the pancreatic islets (Fig. 1A,B). The staining for factor $\mathrm{H}$ was always prominent in the islets of Langerhans with a clear granular pattern (Fig. 1B), but it could also be seen in some exocrine acini (Fig. 1C). When absorption controls were performed to confirm these observations, no diminution of the staining was seen. Interestingly though, attempts to pre-absorb the primary antibodies with purified factor $\mathrm{H}$ in liquid phase produced a paradoxical increase in staining intensity. To overcome these difficulties, we purified the commercial antibodies with a factor $\mathrm{H}$ affinity column and when the eluate was used for immunohistochemistry it showed the exact same pattern as the unprocessed serum (Fig. 1D). The purified antibody could now be preabsorbed by solid-phase methods resulting in a total quenching of the staining (Fig. 1E). Nevertheless, the liquid-phase absorption attempts still produced the paradoxical reaction (Fig. 1F), possibly due to the building of 

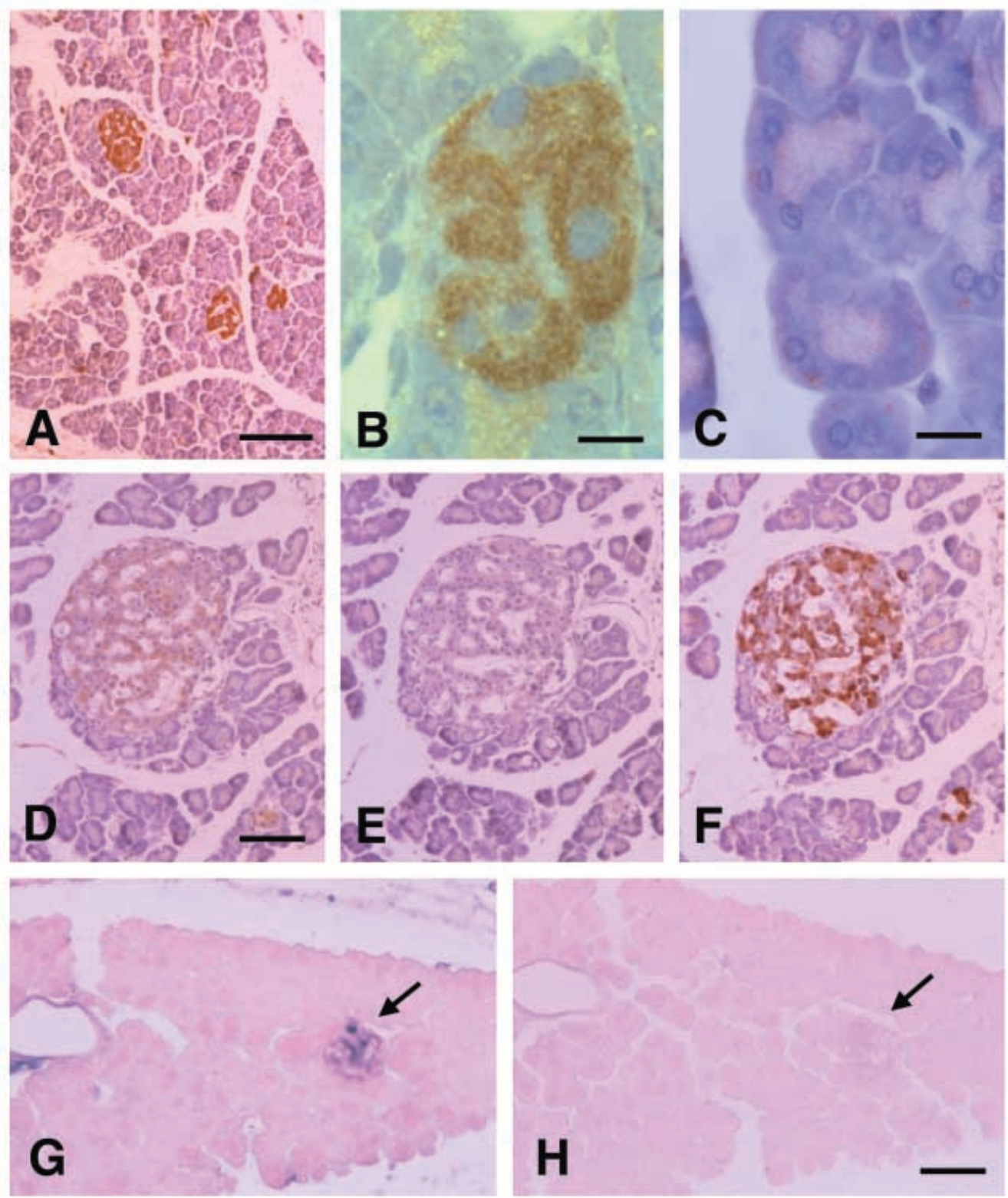

Figure 1 Distribution of factor $\mathrm{H}$ immunoreactivity in the rat pancreas as seen by immunohistochemical and in situ hybridization methods. Antibodies against factor $\mathrm{H}$ stained cells in the islets of Langerhans (A), which presented a granular pattern at higher magnification (B). Sporadically, some exocrine acini were also stained with the anti-factor $\mathrm{H}$ antibodies (C). Affinity-purified antibodies showed the same pattern of staining (D), which was totally abolished after solid-phase pre-absorption (E), but produced a paradoxical labeling increase after absorption in liquid phase $(\mathrm{F})$. Serial sections showing that the antisense probe for factor $\mathrm{H}$ labeled mainly the pancreatic islets $(G)$, while the sense probe did not produce any staining $(H)$. The arrows point to the same islet of Langerhans in the consecutive sections. A, Bar $=100 \mu \mathrm{m} ; \mathrm{B}$, bar $=5 \mu \mathrm{m} ; \mathrm{C}$, bar $=10 \mu \mathrm{m} ; \mathrm{D}-\mathrm{F}, \operatorname{bar}=50 \mu \mathrm{m}$; $\mathrm{G}$ and $\mathrm{H}$, bar $=50 \mu \mathrm{m}$.

large antibody-antigen complexes in the immunoreactive sites, as has been previously described for other epitopes (Larsson 1988).

To make sure our antibody was recognizing rat factor $\mathrm{H}$, a Western blot experiment was run with rat plasma (Fig. 2). The antibody identified a single band both in the lane of human purified factor $\mathrm{H}$ and in the lanes where rat plasma was loaded. A small difference in size was observed, with the rat band being slightly smaller than human factor $\mathrm{H}$. 


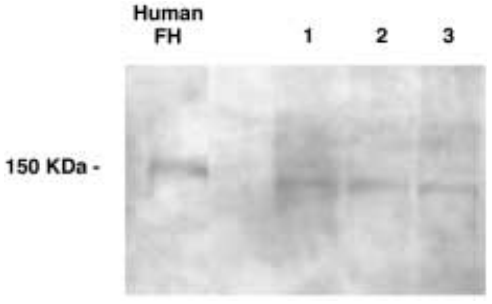

Figure 2 Western blot analysis of purified human factor $\mathrm{H}$ (50 ng) and rat plasma $(1 \mu \mathrm{l})$ from three different animals $(1-3)$. The antibody used here is the same used in the immunohistochemical analysis, goat anti-human factor $\mathrm{H}$, at 1:2000 dilution. The apparent size of human factor $\mathrm{H}$ under reducing conditions is $150 \mathrm{kDa}$. The rat immunoreactive band is slightly smaller.

To identify the cell type responsible for the factor $\mathrm{H}$ immunoreactivity, multiple immunofluorescence followed by confocal microscopy was performed. In all cases, factor
$\mathrm{H}$ immunoreactivity was co-localized with insulin in the center of the pancreatic islets, whereas the peripheral cell types containing somatostatin, glucagon, or pancreatic polypeptide did not contain the factor $\mathrm{H}$-like epitope (Fig. 3).

This observation was further confirmed by double immunogold staining under the electron microscope. Both insulin and factor $\mathrm{H}$ immunoreactivities were found in the secretory granules of the $\beta$ cells and were absent from the other endocrine cell types (Fig. 4A). Interestingly, the small gold particles decorating the anti factor $\mathrm{H}$ antibody were preferentially located in the electron-lucent haloes of the secretory granules, whereas the larger gold particles labeling insulin were mostly found in the dense cores (Fig. 4B). Occasionally, some factor $\mathrm{H}$ immunoreactivity was found in the larger secretory granules of the exocrine cells (Fig. 4C), corroborating the light microscopic observations.
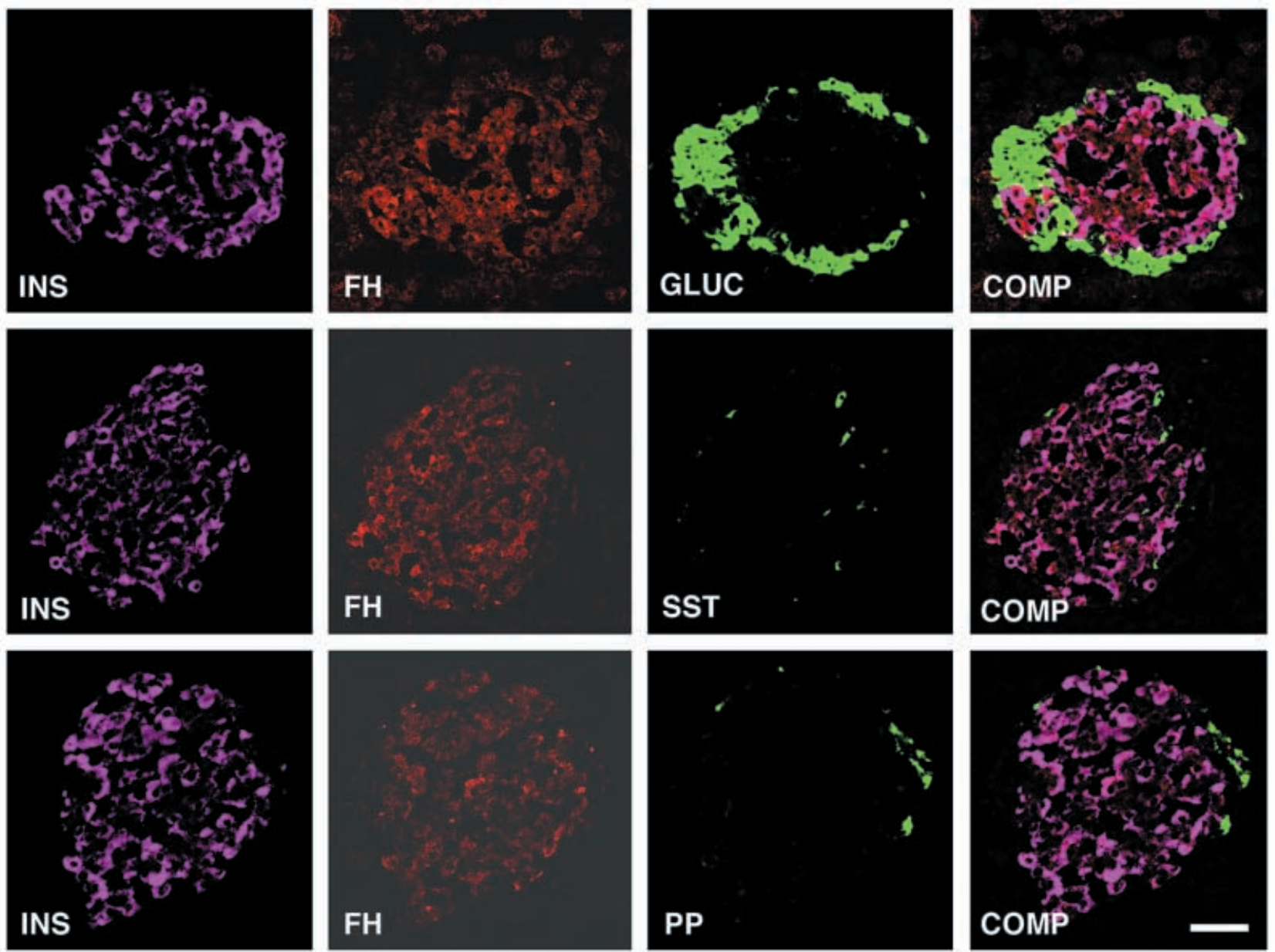

Figure 3 Triple immunofluorescence for insulin (purple), factor $\mathrm{H}$ (red), and other classical pancreatic hormones (green) in paraffinembedded sections of rat pancreas. The fourth column represents a composite of the previous three images. In all cases factor $\mathrm{H}$ (FH) co-localizes with insulin (INS) in the central $\beta$ cells and is absent from the peripheral cells which produce somatostatin (SST), glucagon (GLUC), or pancreatic polypeptide (PP). Confocal microscopy. Bar $=20 \mu \mathrm{m}$. 

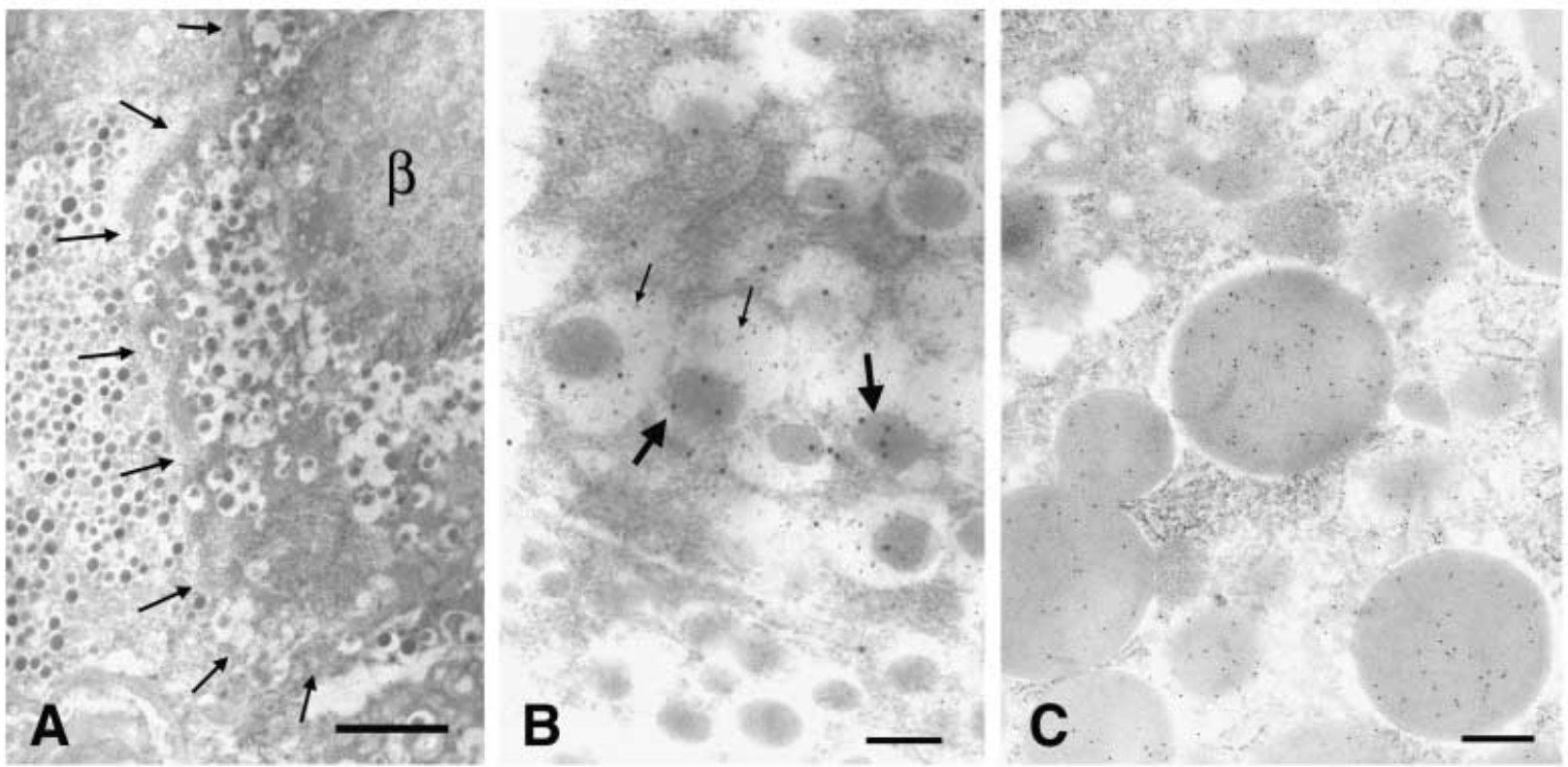

Figure 4 Double immunoelectron microscopy for factor $\mathrm{H}$ (small gold particles, $10 \mathrm{~nm}$ in diameter) and insulin (large particles, $20 \mathrm{~nm}$ ) in rat pancreas. Low magnification images (A) show that immunoreactive cells have the characteristic morphology of the $\beta$ cells $(\beta$, arrows show the limits of the cell). A higher magnification of the secretory granules (B) shows that factor $\mathrm{H}$ immunoreactivity is predominantly found in the electron lucent haloes (small arrows) while insulin-associated gold particles are mainly in the dense granule cores (large arrows). The secretory granules of some exocrine cells were also labeled for factor $\mathrm{H}$ but not for insulin $(\mathrm{C}) . \mathrm{A}, \mathrm{Bar}=2 \mu \mathrm{m}$; B and $\mathrm{C}$, bar $=0 \cdot 2 \mu \mathrm{m}$.

\section{Expression of factor $H m R N A$ in the pancreas}

The existence of immunoreactivity for a protein does not necessarily imply that such protein is expressed in that particular site. The immunoreactivity could be due to the presence of an unrelated epitope or the protein may have been captured by the cell from an external source. The second possibility was especially concerning since factor $\mathrm{H}$ circulates in the blood in high concentration and the islets are well irrigated. To investigate the intrinsic expression of factor $\mathrm{H}$ in the pancreas, an RT-PCR experiment was performed in mouse tissue. Figure 5 shows that a specific band for factor $\mathrm{H}$ was found after amplification of pancreatic cDNA. Sequencing of the band demonstrated $100 \%$ identity with the published sequence of mouse factor H (Kristensen \& Tack 1986), further demonstrating the expression of factor $\mathrm{H}$ in the pancreas. In addition, in situ hybridization with an antisense riboprobe labeled mainly the pancreatic islets (Fig. 1G), whereas the sense probe did not produce any significant staining (Fig. 1H).

\section{Regulation of insulin release}

Addition of exogenous AM to isolated islets resulted in a significant decrease of insulin release (Fig. 6A) mediated through elevation of cAMP (Fig. 6B), as previously reported (Martínez et al. 1996). The addition of factor $\mathrm{H}$ in the presence of AM produced a dose-dependent further reduction of insulin secretion (Fig. 6A) with concomitant elevations of cAMP (Fig. 6B). Factor $\mathrm{H}$ alone also showed some effect on lowering insulin release from the islets (Fig. 6A).

\section{Discussion}

In this study we show that the AM binding protein, complement factor $\mathrm{H}$, is expressed in the pancreas and that it contributes to the regulation of insulin secretion.

The major source of complement factor $\mathrm{H}$ seems to be the liver, although a variety of other tissues and cell types have been shown to express this blood component (Friese et al. 1999). Here we show that the pancreas, and especially the $\beta$ cells in the center of the islets of Langerhans, are another source for factor $\mathrm{H}$. The specificity of the immunohistochemical staining pattern was confirmed by solid-phase absorption of the affinitypurified antibody and also by the paradoxical increase in intensity after liquid-phase absorption, since this phenomenon only happens when a specific antibody-antigen interaction takes place, augmenting staining via cascade cross-linking of immune complexes (Larsson 1988). Western blot analysis of rat plasma showed a single positive band with a size slightly smaller than human factor $\mathrm{H}$, possibly due to species variations as reported for the AM 


\section{Eth. Br.}
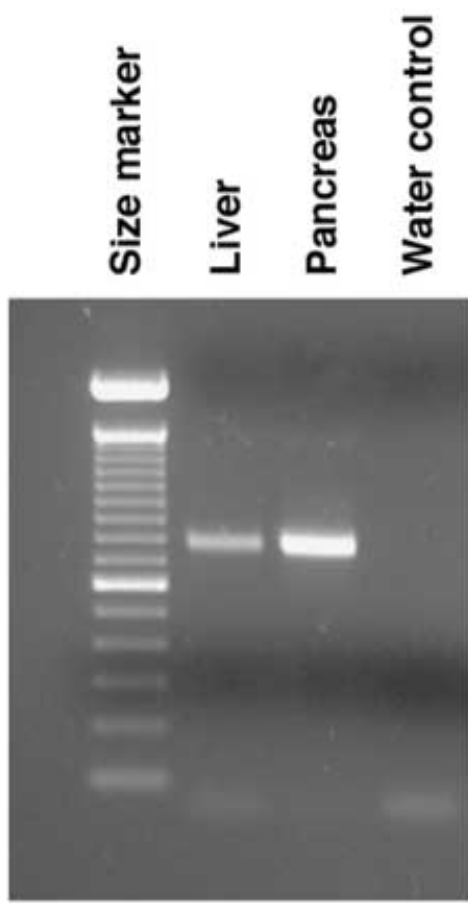

\section{Southern}

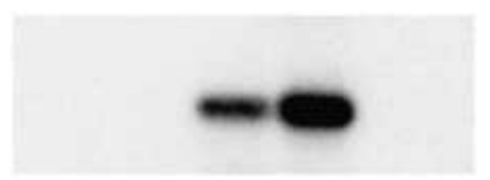

Figure 5 RT-PCR experiment performed on CDNA from mouse liver and pancreas. Specific primers for factor $\mathrm{H}$ produced the expected $839 \mathrm{bp}$ band. Sequencing of the PCR products confirmed their identity with mouse factor $\mathrm{H}$. Eth. Br., ethidium bromide. binding protein by Elsasser et al. (1999). The specificity of the RT-PCR band obtained from mouse pancreatic extracts was also verified by base sequencing.

Factor $\mathrm{H}$ and insulin immunoreactivities were found in the same secretory granules, but interestingly, with a different suborganellar distribution. A comparable fact was reported for glicentin and glucagon-like peptides in the secretory granules of the neighboring $\alpha$ cells (Varndell et al. 1985). Whether this unusual localization has any physiological meaning is difficult to address and may just reflect a differential precipitation behavior during tissue fixation.

Physiologically, the production of factor $\mathrm{H}$ by the $\beta$ cells seems to be related with the regulation of insulin release. In the presence of extrinsic AM, factor $\mathrm{H}$ induces a dose-dependent inhibition of insulin secretion accompanied by an elevation in cAMP. This observation is in agreement with previous experiments done in Rat2 cells, in which exogenous factor $\mathrm{H}$ augments AM induced cAMP production (Pío et al. 2001). These results suggest that factor $\mathrm{H}$ may act as a chaperone molecule which facilitates the binding of AM to its receptor. This has been suggested for other activating binding proteins such as insulin-like growth factor binding proteins (Hwa et al. 1999). Moreover, some membrane components have been shown to bind factor H (Pangburn et al. 1991, DiScipio et al. 1998, Malhotra et al. 1999), and we can envisage a mechanism by which factor $\mathrm{H}$ and $\mathrm{AM}$ bind in solution and then the attachment of factor $\mathrm{H}$ to its membrane binding site would bring AM in the proximity of its own receptor.

An intriguing observation is that factor $\mathrm{H}$ by itself is able to elicit a weak response from the isolated islets, whereas it

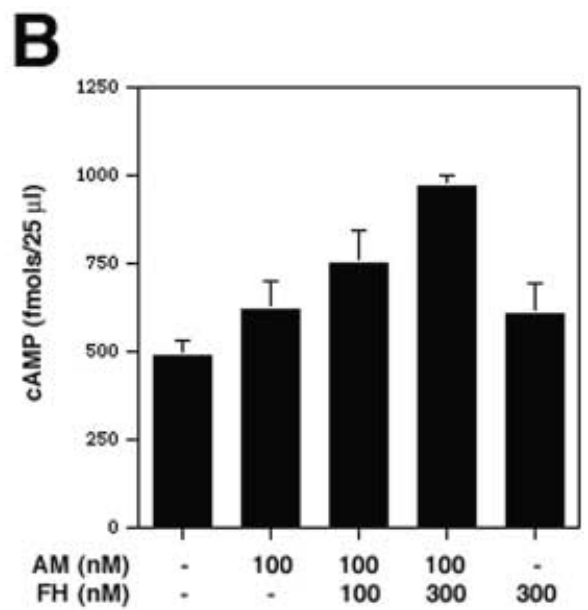

Figure 6 Physiological actions of factor $\mathrm{H}(\mathrm{FH})$ on insulin secretion. Treatments with $\mathrm{AM}$ and/or factor $\mathrm{H}$ resulted in dose-dependent decreases in insulin secretion $(A)$ and concomitant elevations of cAMP in the isolated islets (B). Values for each treatment represent the mean and standard deviation of three independent wells. Insulin release is expressed as the ratio between the concentration in the high glucose medium divided by the amount in the low glucose one to allow for variations in the number of secreting cells and/or their secretory efficiency. All values were statistically different $(P<0.05)$ from the control (first bar). 
did nothing in the Rat 2 experiments (Pío et al. 2001). This apparent discrepancy may be due to differences in the exposure time of the assays. Incubations of $5 \mathrm{~min}$ are sufficient to evoke cAMP changes, whereas in the islet experiments the incubation time with the antisecretagogues was $45 \mathrm{~min}$. In that time a considerable amount of AM could be secreted from the islets, as can be demonstrated by adding a monoclonal anti-AM antibody (MoAbG6) which results in a great increase in insulin secretion over untreated controls (Martínez et al. 1996). At this time we can not exclude an AM-independent effect for factor $\mathrm{H}$ on insulin secretion and that they have an additive effect rather than acting through a protein-protein interaction. Nevertheless, the fact remains that factor $\mathrm{H}$ influences this important physiological phenomenon.

Other complement components have been indirectly implicated in the reduction of insulin release. For instance, $\mathrm{C} 1 \mathrm{q}$ and $\mathrm{C} 3$ seem to be responsible for the insulin secretion suppression induced by serum from newly diagnosed type 2 diabetic patients (Conroy et al. 2000).

Another aspect of factor $\mathrm{H}$ physiology that may make it important for pancreatic integrity is its capacity to suppress complement-mediated cell lysis. It has been shown that some bacteria which are able to recruit factor $\mathrm{H}$ in their surface are less sensitive to lysis (Neeleman et al. 1999). The same mechanism is used by tumor cells that express factor $\mathrm{H}$ and escape immune surveillance through the inhibition of the complement system (Fedarko et al. 2000, Junnikkala et al. 2000). It could be possible that $\beta$ cells are normally protected by secreting factor $\mathrm{H}$, and that under conditions reducing expression of this inhibitory protein they may become more susceptible to complementmediated lysis. This process may ultimately result in type 1 diabetes. The complement inhibitory role of factor $\mathrm{H}$ is more potent in the presence of AM (Pío et al. 2001) and, in the pancreas, AM is readily available. The protective role of AM against harmful immune reactions has been demonstrated in a mouse model that overexpresses AM in the cardiovascular system. The transgenic mice were less likely to die from lipopolysaccharide-induced shock than their wild-type littermates (Shindo et al. 1999). Whether this protection is mediated through factor $\mathrm{H}$ remains to be investigated.

Important variations have been found in the circulating concentrations of complement components in type 1 and 2 diabetic patients (Vialettes et al. 1983, Sundsmo et al. 1985, Charlesworth et al. 1987, Titov et al. 1987, Ebeling et al. 1999), but so far factor $H$ has not been studied in detail. Future studies focusing on this molecule may enlighten our understanding of the effects of factor $\mathrm{H}$ in metabolic diseases.

The finding of factor $\mathrm{H}$ immunoreactivity in the secretory granules of the exocrine acinar cells suggests that factor $\mathrm{H}$ is also a component of the pancreatic fluid and that it may play some role in intestinal physiology. Other components of the complement system are synthesized and secreted in the exocrine pancreas. These include C3, C4, and factor B (Sumiyoshi et al. 1997).

As new regulatory molecules are added to the number of physiological switches of insulin release, the components of the glycemia homeostasis equation grow exponentially larger, adding new targets for pharmacological intervention in metabolic disorders such as diabetes and obesity.

\section{Acknowledgements}

We thank Dr F Urbano (Electron Microscopy Center, School of Medicine, Universidad Autónoma de Madrid) for the use of his facility. Monoclonal antibodies against somatostatin, glucagon and pancreatic polypeptide were kindly provided by Dr H C Wong (CURE/UCLA/DDC Antibody-RIA Core, NIH Grant DK41301). R Pío was supported by a training grant (98/9172) from Instituto de Salud Carlos III, Ministerio de Sanidad y Consumo, Spain.

\section{References}

Charlesworth JA, Timmermans V, Golding J, Campbell LV, Peake PW, Pussell BA, Wakefield D \& Howard N 1987 The complement system in type 1 (insulin-dependent) diabetes. Diabetologia 30 372-379.

Conroy SJ, Abdel-Wahab YH, Caraher EM, Byrne PM, Murphy E, Nolan J, Flatt PR \& Newsholme P 2000 Evidence for complement-dependent and -independent inhibition of insulin secretion from clonal beta-cells incubated in the presence of sera of newly diagnosed IDDM patients. Journal of Endocrinology 164 139-147.

DiScipio RG, Daffern PJ, Schraufstatter IU \& Sriramarao P 1998 Human polymorphonuclear leukocytes adhere to complement factor $\mathrm{H}$ through an interaction that involves $\alpha_{\mathrm{M}} \beta_{2}(\mathrm{CD} 11 \mathrm{~b} / \mathrm{CD} 18)$. Journal of Immunology 160 4057-4066.

Ebeling P, Teppo AM, Koistinen HA, Viikari J, Ronnemaa T, Nissen M, Bergkulla S, Salmela P, Saltevo J \& Koivisto VA 1999 Troglitazone reduces hyperglycaemia and selectively acute-phase serum proteins in patients with type II diabetes. Diabetologia $\mathbf{4 2}$ 1433-1438.

Elsasser TH, Kahl S, Martínez A, Montuenga LM, Pío R \& Cuttitta F 1999 Adrenomedullin binding protein in the plasma of multiple species: characterization by radioligand blotting. Endocrinology 140 4908-4911.

Fedarko NS, Fohr B, Robey PG, Young MF \& Fisher LW 2000 Factor $\mathrm{H}$ binding to bone sialoprotein and osteopontin enables tumor evasion of complement-mediated attack. Journal of Biological Chemistry 275 16666-16672.

Friese MA, Hellwage J, Jokiranta TS, Meri S, Peter HH, Eibel H \& Zipfel PF 1999 FHL-1/reconectin and factor H: two human complement regulators which are encoded by the same gene are differently expressed and regulated. Molecular Immunology 36 809-818.

Hwa V, Oh Y \& Rosenfeld RG 1999 The insulin-like growth factorbinding protein (IGFBP) superfamily. Endocrine Reviews 20 761-787.

Junnikkala S, Jokiranta TS, Friese MA, Jarva H, Zipfel PF \& Meri S 2000 Exceptional resistance of human H2 glioblastoma cells to complement-mediated killing by expression and utilization of factor $\mathrm{H}$ and factor $\mathrm{H}$-like protein 1. Journal of Immunology 164 6075-6081. 
Kristensen T \& Tack BF 1986 Murine protein H is comprised of 20 repeating units, 61 amino acids in length. PNAS $\mathbf{8 3}$ 3963-3967.

Larsson LI 1988 Immunocytochemistry: Theory and Practice. Boca Raton, Florida: CRC Press.

López J, Cuesta N, Cuttitta F \& Martínez A 1999 Adrenomedullin in non-mammalian vertebrate pancreas: an immunocytochemical study. General and Comparative Endocrinology 115 309-322.

Malhotra R, Ward M, Sim RB \& Bird MI 1999 Identification of human complement factor $\mathrm{H}$ as a ligand for L-selectin. Biochemical Journal 341 61-69.

Martínez A, Weaver C, López J, Bhathena SJ, Elsasser TH, Miller MJ, Moody TW, Unsworth E \& Cuttitta F 1996 Regulation of insulin secretion and blood glucose metabolism by adrenomedullin. Endocrinology $1372626-2632$.

Martínez A, Cuttitta F \& Teitelman G 1998 Expression pattern for adrenomedullin during pancreatic development in the rat reveals a common precursor with other endocrine cell types. Cell and Tissue Research 293 95-100.

Martínez A, Elsasser TH, Bhathena SJ, Pío R, Buchanan TA, Macri CJ \& Cuttitta F 1999 Is adrenomedullin a causal agent in some cases of type 2 diabetes? Peptides 20 1471-1478.

Martínez A, Kapas S, Miller MJ, Ward Y \& Cuttitta F 2000 Coexpression of receptors for adrenomedullin, calcitonin generelated peptide, and amylin in pancreatic $\beta$-cells. Endocrinology 141 406-411.

Neeleman C, Geelen SP, Aerts PC, Daha MR, Mollnes TE, Roord JJ, Posthuma G, van Dijk H \& Fleer A 1999 Resistance to both complement activation and phagocytosis in type 3 pneumococci is mediated by the binding of complement regulatory protein factor H. Infections and Immunity 67 4517-4524.

Pangburn MK, Atkinson MA \& Meri S 1991 Localization of the heparin-binding site on complement factor H. Journal of Biological Chemistry 266 16847-16853.
Pío R, Martínez A, Unsworth EJ, Kowalak JA, Bengoechea JA, Zipfel PF, Elsasser TH \& Cuttitta F 2001 Complement factor H is a serum binding protein for adrenomedullin. The resulting complex modulates the bioactivities of both partners. Journal of Biological Chemistry 276 12292-12300.

Shindo T, Maemura K, Kurihara Y, Kuwaki T, Izumida T, Minamino N, Kangawa K, Kumada M \& Kurihara H 1999 Adrenomedullin gene engineering in mice reveals its roles in circulatory homeostasis and reproduction. Circulation 100 (Suppl S) 196.

Sumiyoshi K, Andoh A, Fujiyama Y, Sakumoto H \& Bamba T 1997 Biosynthesis and secretion of MHC class III gene products (complement C4 and factor B) in the exocrine pancreas. Journal of Gastroenterology 32 367-373.

Sundsmo JS, Papin RA, Wood L, Hirani S, Waldeck N, Buckingham B, Kershnar A, Ascher M \& Charles MA 1985 Complement activation in type 1 human diabetes. Clinical Immunology and Immunopathology 35 211-225.

Titov LP, Korvigo GV, Kharitonik GD \& Semenov GV 1987 Levels of various components of the classical and alternative pathways of complement activation in diabetes mellitus patients. Problemy Endokrinologii 33 9-13.

Varndell IM, Bishop AE, Sikri KL, Uttenthal LO, Bloom SR \& Polak JM 1985 Localization of glucagon-like peptide (GLP) immunoreactants in human gut and pancreas using light and electron microscopic immunocytochemistry. Journal of Histochemistry and Cytochemistry 33 1080-1086.

Vialettes B, Lassmann V \& Vague P 1983 Decrease in the serum level of the $\mathrm{C} 3$ complement component in noninsulin dependent diabetes of recent onset. Diabete et Metabolisme 9 66-68.

Received 24 January 2001

Accepted 30 May 2001 